\title{
Factors Associated with Clinical Outcomes of Palliative Stenting for Malignant Colonic Obstruction
}

\author{
Sang-Jae Kwon, Jiyoung Yoon, Eun Hye Oh, Jeongseok Kim, Nam Seok Ham, Sung Wook Hwang, \\ Sang Hyoung Park, Byong Duk Ye, Jeong-Sik Byeon, Seung-Jae Myung, Suk-Kyun Yang, and Dong-Hoon Yang \\ Department of Gastroenterology, Asan Medical Center, University of Ulsan College of Medicine, Seoul, Korea
}

\section{Article Info}

Received May 8, 2020

Revised August 10, 2020

Accepted August 14, 2020

Published online November 2, 2020

Corresponding Author

Dong-Hoon Yang

ORCID https://orcid.org/0000-0001-7756-2704

E-mail dhyang@amc.seoul.kr

\begin{abstract}
Background/Aims: Self-expandable metal stents (SEMSs) can be applied to relieve colorectal obstruction secondary to incurable primary colorectal cancer or extracolonic malignancy. We aimed to identify factors associated with clinical success and the reintervention-free survival (RFS) after palliative stenting.

Methods: Cases of palliative SEMS placement between 2005 and 2019 were retrieved from the institutional database and reviewed retrospectively. Logistic regression and log-rank testing followed by Cox proportional hazard analyses were performed to investigate the predictors of the clinical success of palliative stenting and factors associated with RFS, respectively.

Results: A total of 593 patients underwent palliative stenting for malignant colonic obstruction (MCO). The technical and clinical success rates were $92.9 \%$ and $83.5 \%$, respectively. Peritoneal carcinomatosis was a predictor of clinical failure (odds ratio, $0.33 ; 95 \%$ confidence interval [Cl], 0.17 to 0.65 ) in the multivariate analysis. Peritoneal carcinomatosis (hazard ratio [HR], 2.48; 95\% $\mathrm{Cl}, 1.69$ to 3.64 ) and stent expansion $>90 \%$ on day 1 (HR, $1.62 ; 95 \% \mathrm{Cl}, 1.05$ to 2.50 ) were associated with a shorter RFS. Neither clinical success nor RFS was associated with extracolonic malignancy. Re-obstruction, stent migration, and perforation were responsible for most reinterventions after clinically successful palliative stenting.

Conclusions: In patients requiring palliative stenting for $\mathrm{MCO}$, peritoneal carcinomatosis was associated with both clinical failure and short RFS. Stent expansion $>90 \%$ on postprocedural day 1 was another predictor of a short RFS after clinically successful stenting. A large prospective study is warranted to establish factors associated with RFS after successful palliative stenting for MCO. (Gut Liver 2021;15:579-587)
\end{abstract}

Key Words: Self-expandable metal stents; Colorectal neoplasms; Malignant colonic obstruction

\section{INTRODUCTION}

Malignant colonic obstruction (MCO) in a palliative setting requires therapeutic intervention irrespective of whether it is associated with incurable primary colorectal cancer (CRC) or extracolonic malignancy. In this situation, either self-expandable metal stent (SEMS) placement or palliative surgery can be an option for relieving the obstruction. Previously reported technical success rates of palliative stenting ranged between $88 \%$ and $100 \%{ }^{1-5}$ and clinically successful decompression was achieved in $77.4 \%$ to $94 \%$ of cases. ${ }^{2,5-11}$ Clinically successful decompression was more likely to be achieved after palliative surgery than after SEMS insertion. ${ }^{9-11}$ However, stenting has advantages of shorter hospitalization ${ }^{9-11}$ and lower intensive care unit admission rate ${ }^{9,10}$ compared with palliative surgery. Therefore, stenting is preferred over surgery for palliation of incurable MCO in clinical practice. ${ }^{12}$

Factors associated with the procedural outcomes of stenting have been investigated in previous studies. Cov- 
ered stents increase the risk of stent migration, but uncovered stents are associated with a higher risk of tumor ingrowth during follow-up. ${ }^{4,13-15} \mathrm{~A}$ small stent diameter has also been suggested as a risk factor for stent migration. ${ }^{3,6,16,17}$ Given that migration occurs early in the poststenting period, ${ }^{13}$ covered stents and small-diameter stents may shorten the reintervention-free survival (RFS) duration more than uncovered stents and large-diameter stents, respectively. Peritoneal carcinomatosis is independently associated with low technical and clinical success rates of palliative stenting ${ }^{7,8}$ and predicts shorter life expectancy. ${ }^{8}$ Insufficient stent expansion $(<70 \%)$ at 48 hours after stent insertion has been suggested as a risk factor for stent obstruction during follow-up, ${ }^{18}$ but no subsequent study has evaluated the clinical significance of stent expansion status at an early post-stenting period.

Palliation of MCO after clinically successful stenting should be sustained to improve the quality of life in patients with incurable malignancies. Ideally, in order to avoid additional stenting or palliative surgery, the reintervention-free period should be equal to or longer than the life expectancy of those who require palliative stenting. However, factors associated with prolonged RFS after palliative stenting have not been extensively investigated. Therefore, in this study, we aimed to evaluate not only the factors associated with technical and clinical success but also the factors affecting RFS in the palliative setting of MCO.

\section{MATERIALS AND METHODS}

\section{Study design and enrollment criteria}

This was a retrospective study based on a de-identified database of a single referral center. The Institutional Re- view Board of Asan Medical Center approved this study (IRB number: S2019-1817) and waived the requirement to obtain informed consent. We reviewed all consecutive endoscopic procedures performed with the intention of through-the-scope colorectal SEMS placement from April 2005 to April 2019. Of 1,176 procedures, procedures involving repeated stenting for re-obstruction ( $\mathrm{n}=133)$, stenting for benign strictures $(n=10)$, cancelled stenting due to endoscopically proven luminal patency $(n=57)$, stenting for obstructive CRC with unrecognized colonic microperforation before procedure $(\mathrm{n}=1)$, and stenting as a bridge-tosurgery $(n=382)$ were excluded. Finally, we selected a total of 593 palliative SEMS placement procedures for colorectal obstruction secondary to unresectable primary CRC or colorectal involvement of extracolonic malignancy (Fig. 1).

\section{Stenting procedure}

All SEMSs were inserted by a through-the-scope method under fluoroscopic guidance, after getting informed consent for each procedure. All procedures were performed by expert endoscopists or second-year fellows under expert supervision. Expert endoscopists were defined as the endoscopists who had performed at least 30 SEMS insertions for MCO before stenting of enrolled cases. ${ }^{19}$ Simple abdominal radiography was routinely obtained to confirm the location and expansion status of SEMSs on the day of and the day following the procedure. Various types of SEMS were used during the study period: uncovered Niti-S colonic D type stents (Taewoong Medical, Gimpo, Korea); covered Comvi stents (Taewoong Medical); uncovered WallFlex colonic stents (Boston Scientific, Marlborough, MA, USA); uncovered Hanaro stents (M.I. Tech, Pyeongtaek, Korea); partial covered Hanaro stents (M.I. Tech); uncovered EGIS colorectal stents (S\&G Biotech Inc., Yongin, Korea); or covered EGIS colorectal stents (S\&G

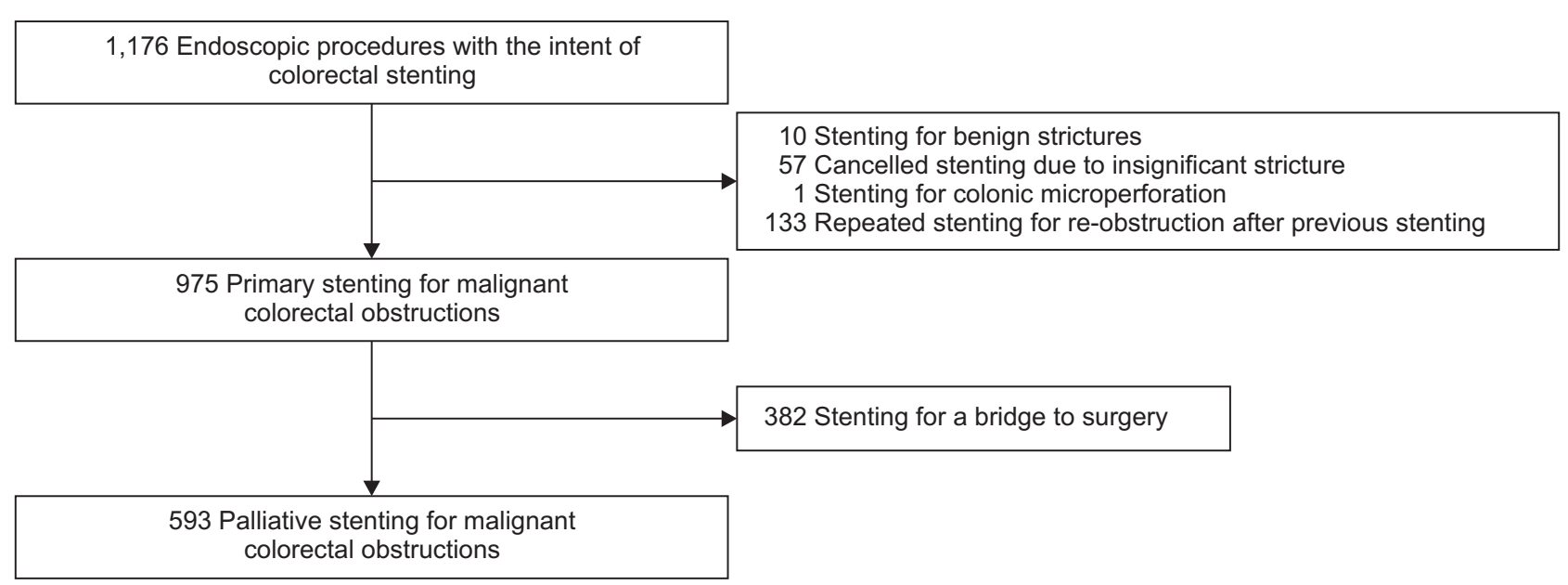

Fig. 1. Retrieval of cases of palliative stenting for colorectal obstruction due to primary colorectal cancer or extracolonic malignancy. 

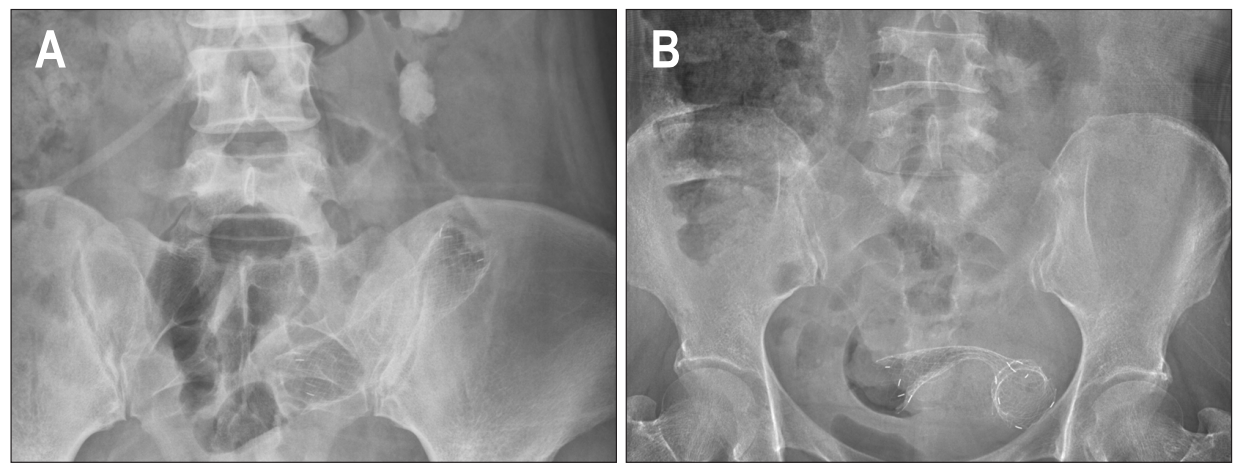

Fig. 2. (A) Stent expansion $>90 \%$ on postprocedural day 1. (B) Stent expansion $<50 \%$ on postprocedural day 1.

Biotech Inc.). Stent type was selected based on each endoscopist's discretion, and stent length was chosen according to the estimated length of the stricture site $(4 \mathrm{~cm}$ longer than the length of stricture).

\section{Variables and outcome measures}

The indications of SEMS placement, type of SEMS, obstruction sites, and technical success were recorded prospectively on the procedure-reporting form for the through-the-scope SEMS placement. Other clinical variables were retrieved retrospectively from electronic medical records.

Technical success was defined as successful stent deployment over the obstructing site without immediate complications. Clinical success was defined as colonic decompression evidenced by radiologic study, relief of obstructive symptoms, and resumption of diet within 48 hours, without additional procedural or operative intervention. Clinical failure was defined when any of the above conditions were not achieved within 48 hours after the procedure. Bleeding was defined as hematochezia with a reduction of hemoglobin $>2 \mathrm{~g} / \mathrm{dL}$ from baseline or hematochezia requiring packed red blood cell transfusion. Perforation was defined as a pneumoperitoneum or pneumoretroperitoneum evidenced by radiologic studies. Colorectal fistula formation was diagnosed according to computed tomography (CT) findings. Stent migration was also confirmed by radiologic studies such as radiography or CT. Re-obstruction was defined as the recurrence of obstructive symptoms as well as endoscopic or radiologic evidence of obstruction. Re-obstruction was categorized into "re-obstruction in situ" (re-obstruction at or around the original site) and "de novo re-obstruction" (re-obstruction at a different site apart from the original stenting site). Reobstruction in situ resulted from tumor ingrowth into the stent, tumor overgrowth collapsing the stent, or disease progression after migration of the stent. De novo re-obstruction was associated with lumen-obstructing metastatic lesions at a different location from the original stenting site. "Reintervention" after clinically successful stenting included repeated stenting, stoma creation, or bowel resection to manage stent-related adverse events or de novo re-obstruction. Peritoneal carcinomatosis was identified based on CT or intraoperative findings. Stent expansion on postprocedural day 1 was calculated as the percentage of the proportion of the narrowest diameter of the stent over the broadest diameter of the stent body based on simple abdominal radiography (Fig. 2).

\section{Statistical analysis}

Statistical analysis was performed using $\mathrm{R}$ version 3.6.0 (R Foundation for Statistical Computing, Vienna, Austria). Categorical variables were analyzed using the chi-square or Fisher exact test. Continuous data were analyzed using the Student t-test or Mann-Whitney U-test. When analyzing predictors of clinical success, univariate and multivariate analyses were performed by logistic regression. Stent survival and hazard ratio were analyzed using Cox proportional hazard analysis. Variables with a p-value $<0.2$ by univariate analysis were included in the multivariate analysis. RFS was analyzed by the log-rank test and plotted as Kaplan-Meier curves. A p-value $<0.05$ was regarded as statistically significant.

\section{RESULTS}

\section{Baseline characteristics}

The median patient age was 60 years (range, 20 to 94 years). The proportion of patients with extracolonic malignancy was $37.1 \%$. Peritoneal carcinomatosis was present in $53.6 \%$ before stenting. Technical and clinical success rates were $92.9 \%$ and $83.5 \%$, respectively. Table 1 describes other detailed characteristics of the overall, technically successful, and clinically successful palliative stenting cases. 
Table 1. Characteristics of Patients Who Underwent Palliative Stenting for Malignant Colonic Obstruction

\begin{tabular}{|c|c|c|c|}
\hline Variable & Overall cases ( $n=593$ ) & Technical success ( $n=551$ ) & Clinical success ( $n=495$ ) \\
\hline Age, yr & $60(20-94)$ & $60(20-94)$ & $61(23-94)$ \\
\hline Male sex & $353(59.5)$ & $333(60.4)$ & $301(60.8)$ \\
\hline $\mathrm{BMI}, \mathrm{kg} / \mathrm{m}^{2 *}$ & $21.5(11.8-34.5)$ & $21.5(13.9-34.5)$ & $21.6(13.9-34.5)$ \\
\hline \multicolumn{4}{|l|}{ ASA class } \\
\hline 1 & $7(1.1)$ & $5(0.9)$ & $5(1.0)$ \\
\hline 2 & $522(88.0)$ & 484 (87.8) & $433(87.5)$ \\
\hline 3 & $59(9.9)$ & 57 (10.3) & 52 (10.5) \\
\hline 4 & $5(0.8)$ & $5(0.9)$ & $5(1.0)$ \\
\hline \multicolumn{4}{|l|}{ Location of obstruction } \\
\hline Left colon & $461(77.7)$ & 429 (77.9) & 385 (77.8) \\
\hline Right colon & $132(22.3)$ & $122(22.1)$ & $110(22.2)$ \\
\hline \multicolumn{4}{|l|}{ Origin of tumor } \\
\hline Colorectum & $373(62.9)$ & $351(63.7)$ & 323 (65.3) \\
\hline Extracolonic & $220(37.1)$ & $200(36.3)$ & $172(34.7)$ \\
\hline Stomach & $151(68.3)$ & $140(69.7)$ & 122 (70.5) \\
\hline Pancreas & $42(19.2)$ & $35(17.4)$ & 32 (18.5) \\
\hline Biliary/hepatocellular & $10(4.5) / 2(0.9)$ & $8(4.0) / 2(1.0)$ & $7(4.1) / 1(0.6)$ \\
\hline Ovary/cervix & $8(3.6) / 4(1.8)$ & $8(4.0) / 4(2.0)$ & $7(4.1) / 1(0.6)$ \\
\hline Urologic & $3(1.4)$ & $3(1.5)$ & $3(1.7)$ \\
\hline Lung & $1(0.5)$ & $1(0.5)$ & 0 \\
\hline \multicolumn{4}{|l|}{ Anti-cancer treatment before stenting } \\
\hline Chemotherapy & $252(42.5)$ & $232(42.1)$ & $202(40.8)$ \\
\hline Combined with bevacizumab & $21(3.5)$ & $19(3.4)$ & $18(3.6)$ \\
\hline Radiotherapy & $29(4.9)$ & $25(4.5)$ & $23(4.6)$ \\
\hline Surgery & $208(35.1)$ & $192(34.8)$ & $169(34.1)$ \\
\hline \multicolumn{4}{|c|}{ Anti-cancer treatment after clinically successful stenting } \\
\hline Chemotherapy & NA & NA & $327(66.1)$ \\
\hline Combined with bevacizumab & NA & NA & $26(5.3)^{+}$ \\
\hline Radiotherapy & NA & NA & $10(2.0)$ \\
\hline Peritoneal carcinomatosis & $318(53.6)$ & $288(52.3)$ & $245(49.5)$ \\
\hline \multicolumn{4}{|l|}{ Type of stent } \\
\hline Covered & $115(19.4)$ & 115 (20.9) & $103(20.8)$ \\
\hline Uncovered & 436 (73.5) & $436(79.1)$ & 392 (79.2) \\
\hline Stent not inserted (technical failure) & $42(7.1)$ & NA & NA \\
\hline \multicolumn{4}{|l|}{ Size of stent, $\mathrm{mm}$} \\
\hline Length & NA & $80(60-160)$ & $80(60-160)$ \\
\hline Diameter & NA & $24(20-25)$ & $24(20-25)$ \\
\hline \multicolumn{4}{|l|}{ Status of SEMS expansion on day 1} \\
\hline$<50 \%$ & NA & 73 (13.2) & 62 (12.5) \\
\hline $50 \%-90 \%$ & NA & $391(71.0)$ & $357(72.1)$ \\
\hline$>90 \%$ & NA & $85(15.4)$ & $76(15.4)$ \\
\hline Day 1 X-ray (not available) & NA & $2(0.4)$ & 0 \\
\hline
\end{tabular}

Data are presented as median (range) or number (\%).

BMI, body mass index; ASA, American Society of Anesthesiologists; SEMS, self-expandable metallic stent; NA, not applicable.

${ }^{*} \mathrm{BMI}$ data were not available in three cases, including two technically successful cases and two clinically successful cases; ${ }^{\dagger}$ After clinically successful palliative stenting, bevacizumab was resumed in two patients who were undergoing bevacizumab-combined chemotherapy before stenting and newly administered in 24 patients who were bevacizumab-naïve before stenting.

\section{Factors associated with technical and clinical success of palliative SEMSs for MCO}

Peritoneal carcinomatosis was associated with technical failure in univariate analysis (odds ratio [OR], 0.44; $95 \%$ confidence interval [CI], 0.22 to $0.87 ; \mathrm{p}=0.019)$, but its association with technical failure did not reach statistical significance in multivariate analysis (OR, 0.50; 95\% CI, 0.24 to 1.03; $\mathrm{p}=0.061$ ) (Table 2). Extracolonic malignancy (OR,
$0.53 ; 95 \% \mathrm{CI}, 0.31$ to $0.93 ; \mathrm{p}=0.026)$ and peritoneal carcinomatosis (OR, 0.30 ; $95 \% \mathrm{CI}, 0.16$ to 0.56 ; $\mathrm{p}<0.001$ ) were associated with clinical failure in univariate analysis, but peritoneal carcinomatosis (OR, 0.33 ; $95 \% \mathrm{CI}, 0.17$ to 0.65 ; $\mathrm{p}=0.001$ ) was the only independent predictor for the clinical failure in multivariate analysis (Table 2). 
Table 2. Factors Associated with the Technical and Clinical Success of Palliative Stenting for Malignant Colonic Obstruction

\begin{tabular}{|c|c|c|c|c|}
\hline \multirow{2}{*}{ Variable } & \multicolumn{2}{|c|}{ Univariate analysis } & \multicolumn{2}{|c|}{ Multivariate analysis } \\
\hline & OR $(95 \% \mathrm{Cl})$ & p-value & OR $(95 \% \mathrm{Cl})$ & p-value \\
\hline \multicolumn{5}{|c|}{ Factors associated with technical success of palliative stenting } \\
\hline Age $(\geq 60 \mathrm{vs}<60 \mathrm{yr})$ & $1.07(0.57-2.01)$ & 0.827 & $0.92(0.47-1.79)$ & 0.811 \\
\hline Sex (female vs male) & $0.60(0.32-1.12)$ & 0.106 & $0.67(0.35-1.29)$ & 0.230 \\
\hline BMI (<21 vs $\left.\geq 21 \mathrm{~kg} / \mathrm{m}^{2}\right)$ & $0.77(0.41-1.46)$ & 0.427 & $0.98(0.50-1.96)$ & 0.965 \\
\hline Origin of tumor (extracolonic vs colonic) & $0.63(0.33-1.18)$ & 0.146 & $0.82(0.39-1.71)$ & 0.596 \\
\hline Location of tumor (right vs left colon) & $0.91(0.44-1.90)$ & 0.802 & & \\
\hline Previous chemotherapy & $0.80(0.43-1.50)$ & 0.487 & & \\
\hline Previous radiotherapy & $0.45(0.15-1.36)$ & 0.159 & $0.53(0.17-1.67)$ & 0.281 \\
\hline Previous surgery & $0.87(0.46-1.66)$ & 0.671 & & \\
\hline Peritoneal carcinomatosis (present vs absent) & $0.44(0.22-0.87)$ & 0.019 & $0.50(0.24-1.03)$ & 0.061 \\
\hline \multicolumn{5}{|c|}{ Factors associated with clinical success after technically successful palliative stenting } \\
\hline Age $(\geq 60 \mathrm{vs}<60 \mathrm{yr})$ & $1.45(0.83-2.54)$ & 0.192 & $1.15(0.64-2.08)$ & 0.636 \\
\hline Sex (female vs male) & $0.86(0.49-1.50)$ & 0.595 & $0.92(0.52-1.66)$ & 0.792 \\
\hline BMI (<21 vs $\left.\geq 21 \mathrm{~kg} / \mathrm{m}^{2}\right)$ & $0.86(0.49-1.49)$ & 0.589 & $1.18(0.64-2.17)$ & 0.591 \\
\hline Origin of tumor (extracolonic vs colonic) & $0.53(0.31-0.93)$ & 0.026 & $0.77(0.38-1.54)$ & 0.455 \\
\hline Location of tumor (right vs left colon) & $1.05(0.53-2.05)$ & 0.892 & & \\
\hline Previous chemotherapy & $0.60(0.34-1.04)$ & 0.069 & $0.86(0.44-1.69)$ & 0.666 \\
\hline Previous radiotherapy & $1.32(0.30-5.73)$ & 0.715 & & \\
\hline Previous surgery & $0.74(0.42-1.31)$ & 0.304 & & \\
\hline Peritoneal carcinomatosis (present vs absent) & $0.30(0.16-0.56)$ & $<0.001$ & $0.33(0.17-0.65)$ & 0.001 \\
\hline Type of stent (covered vs uncovered) & $0.96(0.49-1.89)$ & 0.914 & & \\
\hline Stent length $(\leq 80 \mathrm{~mm})$ & $1.28(0.73-2.22)$ & 0.388 & & \\
\hline Stent diameter ( $\leq 22 \mathrm{~mm})$ & $0.79(0.41-1.50)$ & 0.468 & & \\
\hline
\end{tabular}

$\mathrm{OR}$, odds ratio; $\mathrm{Cl}$, confidence interval; $\mathrm{BMI}$, body mass index; $\mathrm{NA}$, not applicable.

\section{RFS after clinically successful palliative stenting}

During a median of 3 months (range, 0 to 43 months) of follow-up, the RFS rates were $70.3 \%, 51.0 \%$, and $22.2 \%$ at 6 , 12 , and 24 months, respectively. In the univariate analysis, peritoneal carcinomatosis, extracolonic malignancy, prestenting surgery, pre-stenting chemotherapy, body mass index $<21 \mathrm{~kg} / \mathrm{m}^{2}$, bevacizumab treatment after stenting, stent expansion $>90 \%$ on postprocedural day 1 , stent diameter $\leq 22 \mathrm{~mm}$, and covered stents were negatively associated with RFS (Supplementary Fig. 1). However, Cox proportional hazard model showed that peritoneal carcinomatosis (hazard ratio, 2.48; 95\% CI, 1.69 to 3.64; $\mathrm{p}<0.001$ ) and stent expansion $>90 \%$ on postprocedural day 1 (hazard ratio, 1.62 ; $95 \% \mathrm{CI}, 1.05$ to $2.50 ; \mathrm{p}=0.028$ ) were independently predictive of shorter RFS (Table 3 ).

\section{Adverse events and causes of reintervention}

Re-obstruction without stent migration occurred in 116 patients who underwent palliative stenting and 81 clinically successful stenting cases. Stent migration occurred in 65 clinically successful stenting cases and 30 of them underwent reintervention during follow-up: eight at $\leq 14$ days of stent migration and 22 at $>14$ days of stent migration. The stent migration rate was associated with stent expansion on postprocedural day 1 ( $23.5 \%$ vs $11.3 \%$ in those with stent expansion $>90 \%$ and $\leq 90 \%$, respectively; $\mathrm{p}=0.004$ ), stent
Table 3. Cox Proportional Hazard Model for Factors Associated with Shorter Reintervention-Free Survival

\begin{tabular}{lcc}
\hline \multicolumn{1}{c}{ Variables } & HR $(95 \% \mathrm{Cl})$ & $\mathrm{p}$-value \\
\hline Age $(\geq 60 \mathrm{vs}<60 \mathrm{yr})$ & $1.11(0.76-1.61)$ & 0.601 \\
BMI $\left(<21 \mathrm{vs} \geq 21 \mathrm{~kg} / \mathrm{m}^{2}\right)$ & $1.09(0.75-1.58)$ & 0.641 \\
$\begin{array}{l}\text { Origin of tumor (extracolonic vs } \\
\quad \text { colonic) }\end{array}$ & $0.90(0.54-1.49)$ & 0.676 \\
Peritoneal carcinomatosis (present vs & $2.48(1.69-3.64)$ & $<0.001$ \\
$\quad$ absent) & $1.312(0.77-2.23)$ & 0.318 \\
Previous surgery & $1.55(0.99-2.43)$ & 0.055 \\
Chemotherapy before stenting & $1.30(0.59-2.90)$ & 0.518 \\
Radiotherapy before stenting & $0.62(0.28-1.35)$ & 0.225 \\
Bevacizumab after stenting & $1.65(0.91-3.00)$ & 0.102 \\
Type of stent (covered vs uncovered) & $1.19(0.66-2.14)$ & 0.556 \\
Stent diameter $\leq 22$ mm & $1.62(1.05-2.50)$ & 0.028 \\
Stent expansion on day 1 >90\% & & \\
\hline
\end{tabular}

$\mathrm{HR}$, hazard ratio; $\mathrm{Cl}$, confidence interval; $\mathrm{BMI}$, body mass index.

diameter $(23.0 \%$ vs $8.2 \%$ in those with a stent diameter $\leq 22 \mathrm{~mm}$ and $>22 \mathrm{~mm}$, respectively; $\mathrm{p}<0.001$ ), and type of stent $(37.9 \%$ vs $6.6 \%$ in those with covered and uncovered stents, respectively; $\mathrm{p}<0.001)$. Perforation after clinical success occurred in 19 patients (3.8\%). Forty-five patients were treated with bevacizumab before or after stenting: 19 patients treated with bevacizumab before stenting stopped bevacizumab after stenting, two were treated with bevacizumab before stenting and continued bevacizumab after 
stenting, and 24 were newly treated with bevacizumab after stenting. There was no statistical difference in perforation rates between those who were exposed to bevacizumab prior to stenting and those who were not $(2 / 21$ [9.5\%] vs 29/572 [5.1\%]; $\mathrm{p}=0.301$ ). A total of 26 patients underwent de novo or continued bevacizumab treatment after clinically successful stenting. After clinical success, perforation occurred more frequently in those exposed to bevacizum$\mathrm{ab}$ than in those who were not $(15.4 \%$ vs $3.2 \%$; $\mathrm{p}=0.014)$. However, in subgroup analysis of patients who underwent bevacizumab treatment after stenting $(n=26)$ (Fig. 3), ini-

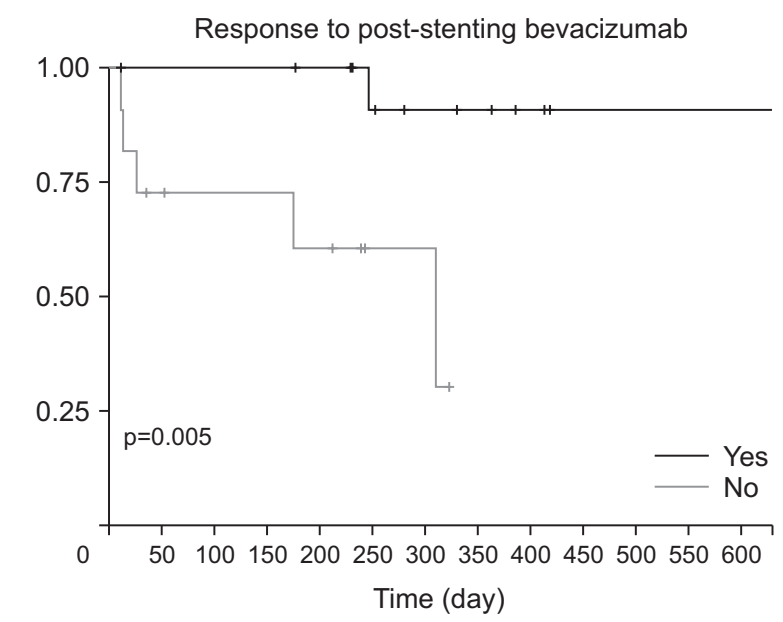

No. at risk

$\begin{array}{llllllllllllll}\text { Yes } & 15 & 14 & 14 & 14 & 13 & 10 & 8 & 7 & 5 & 3 & 3 & 3 & 3\end{array}$

$\begin{array}{lllllrrrrrrrrr}\text { No } & 11 & 7 & 6 & 6 & 5 & 2 & 2 & 0 & 0 & 0 & 0 & 0 & 0\end{array}$

Fig. 3. Reintervention-free survival according to the treatment response within 2 months after bevacizumab-based chemotherapy in patients who were exposed to bevacizumab after palliative stenting. tial responders to bevacizumab at 2 months $(\mathrm{n}=15)$ showed prolonged RFS than nonresponders $(n=11)$. Table 4 shows other details of the complications.

\section{DISCUSSION}

In the current study, peritoneal carcinomatosis was associated with clinical failure of palliative stenting for MCO and with early reintervention after clinically successful palliative stenting for MCO. The negative association of peritoneal carcinomatosis with clinical success has been reported in a previous study ${ }^{8}$ and may result from unveiled synchronous obstruction other than the stenting site or delayed peristalsis due to carcinomatosis. In a similar viewpoint, the association of peritoneal carcinomatosis with shortened RFS in our study may be attributable to the development of metachronous obstruction or deteriorated peristalsis as peritoneal carcinomatosis was aggravated despite the clinical success of initial palliative stenting. The association of extracolonic malignancy with the clinical success of palliative stenting for MCO is still controversial. Several studies reported that an extracolonic malignancy was predictive of the clinical failure of palliative stenting for MCO, ${ }^{6,720}$ while others showed no association with the clinical success of palliative stenting. ${ }^{18,21}$ We found that extracolonic malignancies were associated with the clinical failure of palliative stenting in the univariate analysis but not in the multivariate analysis. Considering the higher frequency of peritoneal carcinomatosis in extracolonic malignancies than in CRC ( $74.1 \%$ vs $41.6 \%$ ) in our study, the association of extracolonic malignancy with the clinical

Table 4. Adverse Events Related to Palliative Stenting in All and Clinically Successful Cases

\begin{tabular}{|c|c|c|c|}
\hline \multirow{2}{*}{ Variable } & \multirow{2}{*}{$\frac{\text { Overall cases }(n=593)}{\text { No. }(\%)}$} & \multicolumn{2}{|r|}{ Clinical success cases ( $n=495$ ) } \\
\hline & & No. $(\%)$ & Days from stenting to complication, median (range) \\
\hline Re-obstruction & $116(19.6)$ & $81(16.4)$ & $129(8-1,333)$ \\
\hline In situ & NA & 71 (14.3) & $129(8-1,333)$ \\
\hline De novo & NA & $9(1.8)$ & $135(9-666)$ \\
\hline Mixed & NA & $1(0.2)$ & 172 \\
\hline Stent migration & $75(12.6)$ & $65(13.1)$ & $68(7-486)$ \\
\hline No intervention required & $35(5.9)$ & $35(7.1)$ & $69(8-486)$ \\
\hline Reintervention required, $\leq 14$ days after migration & $18(3.0)$ & $8(1.6)$ & $35(8-369)$ \\
\hline Reintervention required, >14 days after migration & $22(3.7)$ & $22(4.4)$ & $69(7-232)$ \\
\hline Perforation & $31(5.2)$ & $19(3.8)$ & $24(3-474)$ \\
\hline Intraprocedural & $6(1.0)$ & NA & NA \\
\hline Early ( $\leq 2$ weeks) & $12(2.0)$ & $6(1.2)$ & 9 (3-13) \\
\hline Late (>2 weeks) & $13(2.2)$ & $13(2.6)$ & $41(18-474)$ \\
\hline Bleeding & $3(0.5)$ & $1(0.2)$ & 18 \\
\hline Fistula & $2(0.3)$ & $2(0.4)$ & $177(47-307)$ \\
\hline Abscess & $1(0.2)$ & $1(0.2)$ & 40 \\
\hline
\end{tabular}

NA, not applicable. 
failure of palliative stenting in the univariate analysis seems to result from the association of extracolonic malignancies with peritoneal carcinomatosis.

In our study, a small portion of patients underwent bevacizumab-based chemotherapy before or after clinically successful stenting for MCO. Theoretically, if the progression of an underlying malignancy is effectively controlled with bevacizumab, RFS is more likely to be prolonged. However, the increased risk of perforation after exposure to bevacizumab may shorten RFS. In our study, preprocedural bevacizumab exposure status did not affect RFS according to log-rank testing (Supplementary Fig. 2), and this finding may be associated with no difference in the perforation rate between those exposed to bevacizumab and those not exposed before stenting (9.5\% vs 5.1\%). On the other hand, despite a higher perforation rate in patients exposed to bevacizumab after stenting than in those who were not (15.4\% vs $3.2 \%)$, RFS was not associated with the postprocedural bevacizumab exposure status after clinically successful palliative stenting for MCO in the multivariate analysis. Given that prolonged RFS was observed in bevacizumab-responders of the postprocedural bevacizumabtreated subgroup (Fig. 3), the balance between perforation risk and anti-cancer effects of bevacizumab treatment may affect the duration of RFS in patients who underwent bevacizumab treatment after stenting. A meta-analysis, in which 86 of 4,086 patients were on chemotherapy with bevacizumab, revealed that concomitant bevacizumab was associated with an increased risk of stent-related perforation. ${ }^{22}$ However, according to a recent retrospective study regarding the safety of stents for $\mathrm{MCO}$ in patients treated with bevacizumab, the perforation rate of the bevacizumab group $(1 / 104,0.9 \%)$ was not higher than that of the nonbevacizumab group $(3 / 95,3.2 \%) .{ }^{23}$ To determine the best compromise between the risk of perforation and the benefit of palliative stenting in patients with $\mathrm{MCO}$ who undergo or will undergo bevacizumab treatment, the association of bevacizumab treatment with RFS and stentrelated perforation should be evaluated prospectively in a large-scale study.

In our study, stent expansion $>90 \%$ on postprocedural day 1 was associated with shorter RFS than stent expansion between $50 \%$ and $90 \%$ or $<50 \%$ on postprocedural day 1 . Stent expansion $>90 \%$ on postprocedural day 1 was also associated with a higher migration rate than stent expansion $\leq 90 \%$ on postprocedural day 1 . Therefore, nearly full expansion of the stent on postprocedural day 1 is suggestive of an increased risk of migration and resultant early reintervention. There is one study regarding the association of stent expansion with the clinical outcome that found that insufficient $(<70 \%)$ expansion of the stent at 48 hours after stenting is associated with stent re-obstruction during follow-up. ${ }^{18}$ In our study, stent expansion $<50 \%$ on postprocedural day 1 is associated with more frequent reintervention during an early window of the follow-up period than stent expansion between $50 \%$ and $90 \%$ on postprocedural day 1 (Supplementary Fig. 1), but statistical significance was not reached. Stent expansion status on postprocedural day 1 abdominal radiography could be a simple and useful indicator for predicting reintervention in a palliative setting. However, unlike CT, radiography provides projection images, and therefore, the stent expansion status cannot be measured accurately in cases of asymmetrically expanded stents or oblique projected X-rays. The usefulness of the postprocedural stent expansion status as a predictor for RFS should be validated in additional prospective studies.

Among the three variables related to the stent, such as length, diameter, and type (covered vs uncovered), a stent diameter $\leq 22 \mathrm{~mm}^{3,6,16,17}$ and covered stents ${ }^{15,24}$ were identified as risk factors for stent migration, and thus, these factors may negatively influence RFS. In our study, a stent diameter $\leq 22 \mathrm{~mm}$ and covered stents were associated with an earlier reintervention than a stent diameter $>22 \mathrm{~mm}$ and uncovered stents, respectively, according to univariate analyses. However, in the multivariate analysis, neither showed a significant association with RFS after clinically successful palliative stenting.

Re-obstruction, stent migration, and perforation were responsible for most reinterventions after clinically successful palliative stenting in our study, and the median time from stenting to the occurrence of each adverse event was 129 days (range, 8 to 1,333 days), 68 days (range, 7 to 486 days), and 24 days (range, 3 to 474 days), respectively. Given the widely ranging time period of each event, clinicians should be vigilant of each adverse event during follow-up, especially for patients having peritoneal carcinomatosis and stent expansion $>90 \%$ on postprocedural day 1 .

Compared with previous studies, our study included a larger number of cases and evaluated a more extensive spectrum of variables reveal factors associated with clinical outcomes of palliative stenting for MCO. Moreover, stent expansion status is easy to measure and can be a useful indicator for the risk of early reintervention in daily clinical practice. However, our study has several limitations. First, this is a retrospective study using data collected over 15 years. During such a long period, there were significant changes in palliative chemotherapy regimens, but the impact of changes in chemotherapy on RFS could not be accurately reflected in our results. Second, small number of patients in certain subgroups also limit the reliability the subgroup analysis of RFS according to bevacizumab exposure or radiation therapy before and after stenting. Third, 
because all patients in our study had an incurable stage of malignancy, there were a considerable number of censored cases after stenting owing to cancer-related mortality and loss of follow-up. Nonetheless, the results of our study will help clinicians understand the long-term clinical course after clinically successful stenting for MCO, factors associated with the clinical success of palliative stenting, and risk of reintervention. Fourth, we failed to assess the association of the reintervention-free period with the patient's subjective quality of life owing to the retrospective setting. Although the negative influence of early reintervention on the quality of patients' life is anticipated, the association between the reintervention-free period and types of reintervention (surgery vs repeated stenting) with the quality of life in patients with MCO should be investigated prospectively.

In conclusion, peritoneal carcinomatosis and stent expansion $>90 \%$ on postprocedural day 1 were associated with early reintervention after clinically successful palliative stenting for MCO. The association of these factors with RFS after successful palliative stenting should be further investigated in large prospective studies.

\section{CONFLICTS OF INTEREST}

No potential conflict of interest relevant to this article was reported.

\section{AUTHOR CONTRIBUTIONS}

Conception and design: S.J.K., D.H.Y. Acquisition of data: S.J.K., J.Y., E.H.O., J.K., N.S.H. Analysis: S.J.K., D.H.Y. Interpretation of the data and drafting of the article: S.J.K., D.H.Y. Critical revision of the article for important intellectual content: S.W.H., S.H.P., B.D.Y., J.S.B., S.J.M., S.K.Y., D.H.Y. Final approval of the article: all authors.

\section{ORCID}

Sang-Jae Kwon https://orcid.org/0000-0003-4474-1073 Jiyoung Yoon https://orcid.org/0000-0001-7448-4296 Eun Hye Oh https://orcid.org/0000-0003-4845-9809 Jeongseok Kim https://orcid.org/0000-0003-1007-564X Nam Seok Ham https://orcid.org/0000-0002-6661-4692 Sung Wook Hwang

https://orcid.org/0000-0002-6981-7575

Sang Hyoung Park

https://orcid.org/0000-0002-5366-5749
Byong Duk Ye https://orcid.org/0000-0001-6647-6325

Jeong-Sik Byeon https://orcid.org/0000-0002-9793-6379

Seung-Jae Myung https://orcid.org/0000-0003-0585-4016

Suk-Kyun Yang https://orcid.org/0000-0003-2772-2575

Dong-Hoon Yang

https://orcid.org/0000-0001-7756-2704

\section{REFERENCES}

1. Carne PW, Frye JN, Robertson GM, Frizelle FA. Stents or open operation for palliation of colorectal cancer: a retrospective, cohort study of perioperative outcome and longterm survival. Dis Colon Rectum 2004;47:1455-1461.

2. Faragher IG, Chaitowitz IM, Stupart DA. Long-term results of palliative stenting or surgery for incurable obstructing colon cancer. Colorectal Dis 2008;10:668-672.

3. Small AJ, Coelho-Prabhu N, Baron TH. Endoscopic placement of self-expandable metal stents for malignant colonic obstruction: long-term outcomes and complication factors. Gastrointest Endosc 2010;71:560-572.

4. Sebastian S, Johnston S, Geoghegan T, Torreggiani W, Buckley M. Pooled analysis of the efficacy and safety of self-expanding metal stenting in malignant colorectal obstruction. Am J Gastroenterol 2004;99:2051-2057.

5. Siddiqui A, Cosgrove N, Yan LH, et al. Long-term outcomes of palliative colonic stenting versus emergency surgery for acute proximal malignant colonic obstruction: a multicenter trial. Endosc Int Open 2017;5:E232-E238.

6. Manes G, de Bellis M, Fuccio L, et al. Endoscopic palliation in patients with incurable malignant colorectal obstruction by means of self-expanding metal stent: analysis of results and predictors of outcomes in a large multicenter series. Arch Surg 2011;146:1157-1162.

7. Yoon JY, Jung YS, Hong SP, Kim TI, Kim WH, Cheon JH. Clinical outcomes and risk factors for technical and clinical failures of self-expandable metal stent insertion for malignant colorectal obstruction. Gastrointest Endosc 2011;74:858-868.

8. Park JJ, Rhee K, Yoon JY, et al. Impact of peritoneal carcinomatosis on clinical outcomes of patients receiving self-expandable metal stents for malignant colorectal obstruction. Endoscopy 2018;50:1163-1174.

9. Zhao XD, Cai BB, Cao RS, Shi RH. Palliative treatment for incurable malignant colorectal obstructions: a meta-analysis. World J Gastroenterol 2013;19:5565-5574.

10. Liang TW, Sun Y, Wei YC, Yang DX. Palliative treatment of malignant colorectal obstruction caused by advanced malignancy: a self-expanding metallic stent or surgery? A system review and meta-analysis. Surg Today 2014;44:22-33.

11. Ribeiro IB, Bernardo WM, Martins BDC, et al. Colonic stent 
versus emergency surgery as treatment of malignant colonic obstruction in the palliative setting: a systematic review and meta-analysis. Endosc Int Open 2018;6:E558-E567.

12. van Hooft JE, van Halsema EE, Vanbiervliet G, et al. Selfexpandable metal stents for obstructing colonic and extracolonic cancer: European Society of Gastrointestinal Endoscopy (ESGE) Clinical Guideline. Endoscopy 2014;46:9901053.

13. Choi JH, Lee YJ, Kim ES, et al. Covered self-expandable metal stents are more associated with complications in the management of malignant colorectal obstruction. Surg Endosc 2013;27:3220-3227.

14. Park S, Cheon JH, Park JJ, et al. Comparison of efficacies between stents for malignant colorectal obstruction: a randomized, prospective study. Gastrointest Endosc 2010;72:304310.

15. Zhang Y, Shi J, Shi B, Song CY, Xie WF, Chen YX. Comparison of efficacy between uncovered and covered selfexpanding metallic stents in malignant large bowel obstruction: a systematic review and meta-analysis. Colorectal Dis 2012;14:e367-e374.

16. Kim BC, Han KS, Hong CW, et al. Clinical outcomes of palliative self-expanding metallic stents in patients with malignant colorectal obstruction. J Dig Dis 2012;13:258-266.

17. Im JP, Kim SG, Kang HW, Kim JS, Jung HC, Song IS. Clinical outcomes and patency of self-expanding metal stents in patients with malignant colorectal obstruction: a prospective single center study. Int J Colorectal Dis 2008;23:789-794.
18. Suh JP, Kim SW, Cho YK, et al. Effectiveness of stent placement for palliative treatment in malignant colorectal obstruction and predictive factors for stent occlusion. Surg Endosc 2010;24:400-406.

19. Lee JH, Yoon JY, Park SJ, et al. The learning curve for colorectal stent insertion for the treatment of malignant colorectal obstruction. Gut Liver 2012;6:328-333.

20. Keswani RN, Azar RR, Edmundowicz SA, et al. Stenting for malignant colonic obstruction: a comparison of efficacy and complications in colonic versus extracolonic malignancy. Gastrointest Endosc 2009;69:675-680.

21. Kim JY, Kim SG, Im JP, Kim JS, Jung HC. Comparison of treatment outcomes of endoscopic stenting for colonic and extracolonic malignant obstruction. Surg Endosc 2013;27:272-277.

22. van Halsema EE, van Hooft JE, Small AJ, et al. Perforation in colorectal stenting: a meta-analysis and a search for risk factors. Gastrointest Endosc 2014;79:970-982.

23. Lee JH, Emelogu I, Kukreja K, et al. Safety and efficacy of metal stents for malignant colonic obstruction in patients treated with bevacizumab. Gastrointest Endosc 2019;90:116124.

24. Yang Z, Wu Q, Wang F, Ye X, Qi X, Fan D. A systematic review and meta-analysis of randomized trials and prospective studies comparing covered and bare self-expandable metal stents for the treatment of malignant obstruction in the digestive tract. Int J Med Sci 2013;10:825-835. 